\title{
Immune Monitoring Technology Primer: protein microarray ('seromics')
}

\author{
Jianda Yuan ${ }^{{ }^{*}}$, Ena Wang ${ }^{2}$ and Bernard A. Fox ${ }^{3}$
} Keywords: Immune monitoring, Protein microarray,
Biomarker, Seromics, Autoantibody response

\section{Description of the technology}

Protein microarrays are used to identify targets of drugs, small molecules, and enzyme substrates that may be modified in numerous ways such as by phosphorylation or methylation, to detect protein binding properties, investigate protein-protein interactions, and to define protein-based biomarkers in a high-throughput manner. They are based on the development of DNA microarray techniques and have thousands of purified proteins immobilized on a solid surface. The technique requires a blocking step to be applied to remove any non-specific binding. After incubation of the protein probe (e.g. patient serum) with a suitable tag, visible detection reagents are employed to quantify the corresponding signals. Proteins microarray are classified into three types: analytical, functional and reverse-phase protein microarrays [1]. Functional protein microarrays are widely used because of their commercial availability. As an example, ProtoArray offers a unique approach to analyze the serological response against thousands of proteins ( 9000) simultaneously. ProtoArray does not cover the entire proteome, but a serological analysis of clinical samples using this protein microarray allows high-content "seromics" screening against a substantial portion of the human proteome to identify potential antibody biomarkers and reactivity patterns that may correlate with disease state or treatment response.

A new, emerging protein array that utilizes molecular technology for the detection of protein abundance in serum, other body fluids and cell lysates. This technology is represented by SomaLogic's SOMAmer (Slow Off-rate Modified Aptamer) proteomic assay. This technology combines the properties of antibodies and

\footnotetext{
* Correspondence: yuanj@mskcc.org

${ }^{1}$ Immune Monitoring Core, Ludwig Center for Cancer Immunotherapy, Memorial Sloan Kettering Cancer Center, 1275 York Ave, Box 386, New York, NY 10065, USA

Full list of author information is available at the end of the article
}

traditional aptamers with extremely large specificity assembly. The selected target specific aptamers with specific three-dimensional structure are modified into a "SOMAmer" that provides protein-binding specificity as well as the primary nucleic acid sequence backbones with streptavidin linker attached to beads bind to proteins in the sample mix. The proteins that are bound to their specific SOMAmer reagents are then biotinylated followed by photocleaving of the linker to release the SOMAmer-protein complexes. Via subsequent capture, all biotinylated proteins are bound to a second streptavidin bead followed by denature of SOMAmer-protein targets, protein targeted SOMAmer are collected, labeled, denatured and hybridized to DNA array fabricated by the complementary strand of the SOMAmers. This technology can efficiently, accurately and rapidly identify and quantify over 1000 proteins across approximately eight logs of concentration in small sample volumes. Other protein microarrays are under research level development and not yet widely applied for immune monitoring.

Here, we concentrate on the 'seromics' ProtoArray technology for the following discussion regarding samples and data in detail. The workflow of an example protein microarray is illustrated in Fig. 1, showing the approach for detecting an antibody response in peripheral blood by this platform $[2,3]$.

\section{Type of data obtained/readout}

Similar to DNA microarrays, a potentially large number of fluorescence signals may be obtained from each array depending on the amount and diversity of antibodies or proteins in each sample that may bind to the thousands of proteins coated on each slide. The results of positive controls are used to determine the quality of the assay. A microarray scanner is required to read and quantitate the fluorescence units from each slide, and results can be exported into spreadsheet format. Bioinformatics is essential to handling and processing the large amount of data 


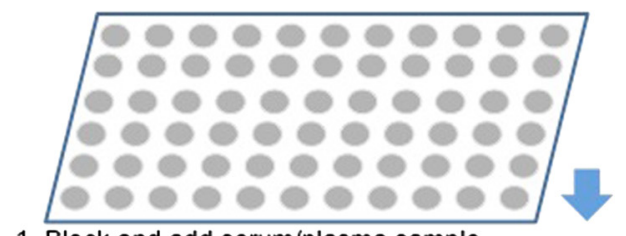

1. Block and add serum/plasma sample

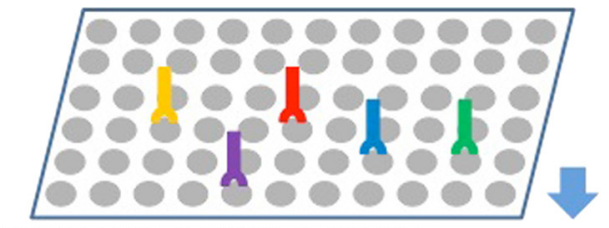

2.Wash and add detecting antibody

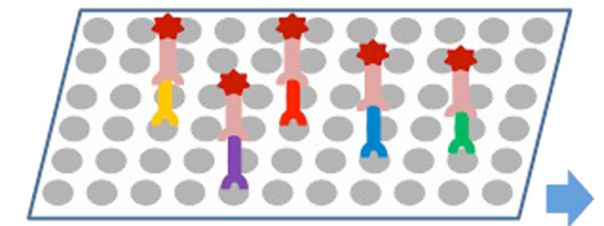

3. Wash, dry and scan
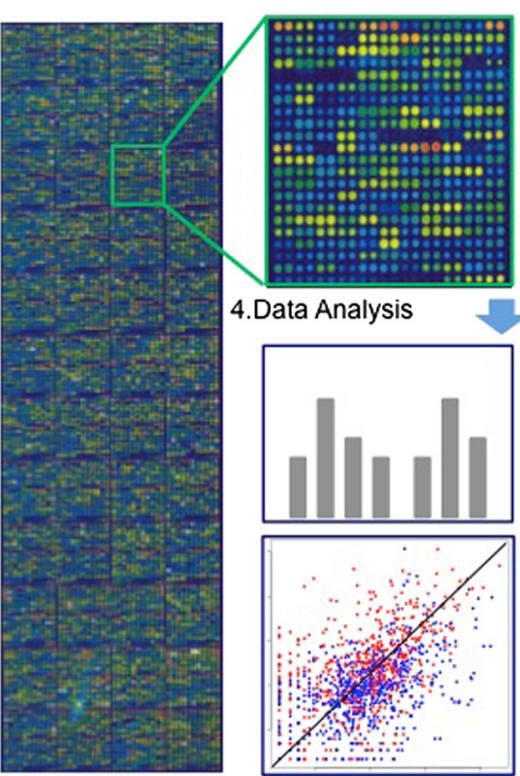

Florescence anti-antibody (detecting secondary)

Fig. 1 Workflow of protein microarray development for the antibody response biomarker profiling. Step 1: Incubate the slides with blocking buffer to reduce non-specific background, then add diluted serum/plasma samples for two hours' incubation. Step 2: Wash the slides with probing/ washing buffer, then incubate fluorescence conjugated anti-human lgG antibody for another two hours. Step 3: Wash slides with probing buffer and deionized water, and dry the slides with centrifugation. After drying, immediately transfer the arrays to a slide carrier of the GenePix $4200 \mathrm{AL}$ fluorescent microarray scanner. Step 4: Scan the array, and analyze the data in GenePix Pro 6.1 software or export the results for additional analysis

obtained through multiple steps including data acquisition, pre-processing, visualization, differential analysis, result verification and computational feature annotation and network analysis. Several software and computational tools have been developed for signal detection, data preprocessing, quality control and data normalization [4-6].

\section{Limitations of the approach}

Different proteins may be coated at different amounts on the slides resulting in potentially different levels of fluorescence signal; therefore the assay is not meant to be quantitative when comparing results between the various proteins. As may be expected from high content analyses, there are also potential non-specific, false positive events that can be found from protein microarray analysis. Therefore, it is critical that the identified antibodies/antigens should be validated by other assays such as western blot, ELISA, Luminex or mass spectrometry. Given the large scale of protein synthesis required for manufacture of the arrays and the ability to run only 1 sample per slide, the assay is relatively expensive which needs to be overcome for more widespread application and use in larger scale clinical trials. The somewhat limited number of proteins coated on the slides (e.g. not all human proteins are present and mutated or modified versions of proteins may not be available), and lack of availability of antibodies in other complimentary platforms to verify specificity of each of the proteins on the slides also currently restricts the broader application of the analytical protein microarray platform.

\section{Types of samples needed and special issues pertaining to samples}

Proper collection and storage of samples and careful standardized sample processing procedure are required to minimize inter- and intra-assay variation and improve the data reproducibility. Frozen serum and plasma samples collected from blood are usually kept in -20 or $-80{ }^{\circ} \mathrm{C}$ freezer for long-term storage to preserve sample stability. Batched pre- and post-therapy sample analyses performed in a single run are recommended to avoid possible differences arising from the inter-assay variation. Samples should not be subjected to multiple freeze-thaw cycles in order to minimize potential degradation of proteins in the sample as well. Special attention should be given to therapeutic agents that may be present in samples as a result of patient 
drug therapy which may interfere with interpretation of results due to interactions with proteins in the arrays.

\section{Level of evidence}

The sensitivity and specificity of a protein microarray were compared to the standard ELISA with a 94\% concordance $[2,3]$. Specific autoantibody responses have been associated with tumor progression for patients with a wide range of cancers [7-9]. Humoral antigen spreading response induced by Sipuleucel-T therapy has been shown to be associated with improved overall survival [10]. Cytotoxic $\mathrm{T}$ lymphocyte antigen-4 (CTLA-4) blockade was showed to induce a larger number of antibody responses in the clinical responders than non-responders in patients with prostate cancer [6]. It was also shown that a prostate cancer patient with a sustained complete response to CTLA-4 blockade mounted a strong humoral response against a small number of proteins [11]. A major question for this technology is whether the development of IgG antibody responses, which require CD4 $\mathrm{T}$ cell help for Ig class-switching, can serve as a surrogate for $\mathrm{T}$ cell immunity [4]. More than 150 papers have been published using this ProtoArray platform in last ten years. Further research is warranted to validate this novel technology and these potential biomarkers sufficiently in the clinical setting for routine clinical application.

\section{Abbreviations}

SOMAmer: Slow Off-rate Modified Aptamer; DNA: Deoxyribonucleic acid; ELISA: Enzyme-linked immunosorbent assay; CTLA-4: Cytotoxic T lymphocyte antigen-4; lgG: Immunoglobulin G.

\section{Competing interests}

The authors declare that they have no competing interests.

\section{Authors' contributions}

$J Y$ and EW drafted the manuscript, and BAF helped to revise the manuscript. All authors read and approved the final manuscript.

\section{Acknowledgments}

This report was supported and enabled by the dedicated work and the members of the Biomarkers Taskforce of the Society for Immunotherapy of Cancer (SITC). We thank Dr. Phillip Wong and Erika Ritter from Immune Monitoring Core at Memorial Sloan Kettering Cancer Center for providing comments and ProtoArray pictures. We also thank Dr. Guene Lynne Thio from Invitrogen Inc. for providing the details about ProtoArray ${ }^{\otimes}$ technology

\section{Author details}

1 Immune Monitoring Core, Ludwig Center for Cancer Immunotherapy, Memorial Sloan Kettering Cancer Center, 1275 York Ave, Box 386, New York, NY 10065, USA. ${ }^{2}$ Sidra Medical and Research Center, PO Box 26999, Doha, Qatar. ${ }^{3}$ Earle A. Chiles Research Institute, Providence Cancer Center, 4805 NE Glisan Street, Portland, OR 97213, USA.

Received: 23 October 2015 Accepted: 4 January 2016

Published online: 19 January 2016

\section{References}

1. Sutandy FX, Qian J, Chen CS, Zhu H. Overview of protein microarrays. Current protocols in protein science / editorial board, John E Coligan [et al.]. 2013; Chapter 27:Unit 271.

2. Gnjatic S, Wheeler C, Ebner M, Ritter E, Murray A, Altorki NK, et al. Seromic analysis of antibody responses in non-small cell lung cancer patients and healthy donors using conformational protein arrays. J Immunol Methods. 2009;341:50-8.

3. Gnjatic S, Ritter E, Buchler MW, Giese NA, Brors B, Frei C, et al. Seromic profiling of ovarian and pancreatic cancer. Proc Natl Acad Sci U S A. 2010; 107:5088-93.

4. Abel L, Kutschki S, Turewicz M, Eisenacher M, Stoutjesdijk J, Meyer HE, et al. Autoimmune profiling with protein microarrays in clinical applications. Biochim Biophys Acta. 1844;2014:977-87.

5. Turewicz M, May C, Ahrens M, Woitalla D, Gold R, Casjens S, et al. Improving the default data analysis workflow for large autoimmune biomarker discovery studies with ProtoArrays. Proteomics. 2013;13:2083-7.

6. Kwek SS, Dao V, Roy R, Hou Y, Alajajian D, Simko JP, et al. Diversity of antigen-specific responses induced in vivo with CTLA-4 blockade in prostate cancer patients. J Immunol. 2012;189:3759-66.

7. Ladd JJ, Chao T, Johnson MM, Qiu J, Chin A, Israel R, et al. Autoantibody signatures involving glycolysis and splicesome proteins precede a diagnosis of breast cancer among postmenopausal women. Cancer Res. 2013;73: 1502-13.

8. Madoz-Gurpide J, Kuick R, Wang H, Misek DE, Hanash SM. Integral protein microarrays for the identification of lung cancer antigens in sera that induce a humoral immune response. Mol Cell Proteomics. 2008;7:268-81.

9. Bouwman K, Qiu J, Zhou H, Schotanus M, Mangold LA, Vogt R, et al. Microarrays of tumor cell derived proteins uncover a distinct pattern of prostate cancer serum immunoreactivity. Proteomics. 2003;3:2200-7.

10. GuhaThakurta D, Sheikh NA, Fan LQ, Kandadi H, Meagher T, Hall SJ, et al. Humoral Immune Response against Nontargeted Tumor Antigens after Treatment with Sipuleucel-T and Its Association with Improved Clinical Outcome. Clin Cancer Res. 2015;21(16):3619-30.

11. Graff JN, Puri S, Bifulco CB, Fox BA, Beer TM. Sustained complete response to CTLA-4 blockade in a patient with metastatic, castration-resistant prostate cancer. Cancer Immunol Res. 2014:2:399-403.

Submit your next manuscript to BioMed Central and we will help you at every step:

- We accept pre-submission inquiries

- Our selector tool helps you to find the most relevant journal

- We provide round the clock customer support

- Convenient online submission

- Thorough peer review

- Inclusion in PubMed and all major indexing services

- Maximum visibility for your research

Submit your manuscript at www.biomedcentral.com/submit
C BioMed Central 